\title{
Computational Design of Advanced Steels
}

\author{
H. K. D. H. Bhadeshia ${ }^{a, b}$ \\ ${ }^{a}$ Graduate Institute of Ferrous Technology, Pohang University of Science and \\ Technology, Pohang 790-784, Republic of Korea \\ ${ }^{\mathrm{b}}$ Materials Science and Metallurgy, University of Cambridge, U.K.
}

\begin{abstract}
The creation and use of computational models is seminal to the design of steels and associated processes and many such models have now become of generic value. We illustrate here a few examples that explain the vitality of the subject and how the methodology is leading to benefits for commerce and academia alike. There are some breathtaking developments which are critically assessed.
\end{abstract}

Key words: steels, computational design, physical metallurgy, fine structures, mathematical modelling

Solids are distinguished from the other states of matter by their mechanical properties, although under appropriate conditions they can exhibit fluid-like phenomena. And these properties depend on a rich hierarchy of structure. The relationship between structure and properties defines materials science as a subject, but this simple interpretation conceals an enormous complexity, which has advantages and disadvantages when it comes to the creation of new materials. One advantage is that there exist anomalies which are as yet unexplained, and hence inspire the search for answers. The disadvantage, particularly in the context of iron and its alloys, is that new discoveries become ever more difficult to access without a depth of knowledge in the subject. It is in this context that computational methods can be indispensable when venturing into unknown territories, and in cases where experiments are simply impossible.

The subject is illustrated here with selected examples, some of which have achieved commercial successes, and other that have revealed new science. It is often the case that models supplement design but are not in themselves adequate to solve the problem completely. Design based on computational methods alone are rare, but one example of that is included. Each of the inventions 
contains original science and has stimulated research in both academia and industry.

\section{Blast-resistant Steel}

Blast resistance describes the ability to maintain structural integrity when faced with a sudden, distributed load. The terms "sudden" and "integrity" imply a need above all for toughness, assuming that strength is easier to achieve. Steels stronger than about $1500 \mathrm{MPa}$ and likely to serve in safetycritical applications are made clean with respect to non-metallic inclusions. Cementite particles then become the prime fracture initiators. A goal in the computational design of blast-resistant steel [1] was therefore to eliminate cementite by controlled alloy-carbide precipitation which leads to finer dispersions by virtue of the need for substitutional solutes to diffuse $[1,2]$. The intended matrix would then be based on a secondary-hardened bainite and martensite mixture, containing dispersed austenite, the stability of which is designed to exploit transformation plasticity.

Saha and Olson considered in their design, the role of each solute with the computational framework illustrated in Fig. 1. There are many details but it revealing blast-resistance per se, as defined in defence-related tests or in academia experiments [3], does not need to be addressed explicitly. This is because not all relevant problems during complex design can be addressed computationally because of the lack of mechanistic knowledge, but clever solutions can nevertheless be achieved using a combination of qualitative experience and computational models. The end product was found to exhibit remarkable combinations of toughness and strength - one aspect is presented in Table 1, which lists the hardness and the austenite stability expressed as the sum of the chemical driving force $\Delta G_{\mathrm{ch}}$ and $W_{\mathrm{f}}$ is an athermal frictional work. These two terms define the stability of the austenite and optimal toughening occurs when the stability is such that martensitic transformation occurs at the ordinary yield strength of the material. The required stability was therefore calculated and the alloy design configured appropriately using computational thermodynamics with appropriate databases, and a deep knowledge of martensite nucleation theory. The comparison in Table 1 also shows that the commercially available materials do not have the right austenite stability to match requirements. The years of work by Olson and coworkers on martensite nucleation theory was seminal in this design. 
Table 1

Hardness and parameters defining the mechanical stability of the austenite [1].

\begin{tabular}{lcc}
\hline Alloy & Vickers hardness & $\Delta G_{\mathrm{ch}}+W_{\mathrm{f}} / \mathrm{J} \mathrm{mol}^{-1}$ \\
\hline AerMet100 & 577 & 4350 \\
AF1410 & 484 & 3600 \\
Design & 389 & 2837 \\
\hline
\end{tabular}

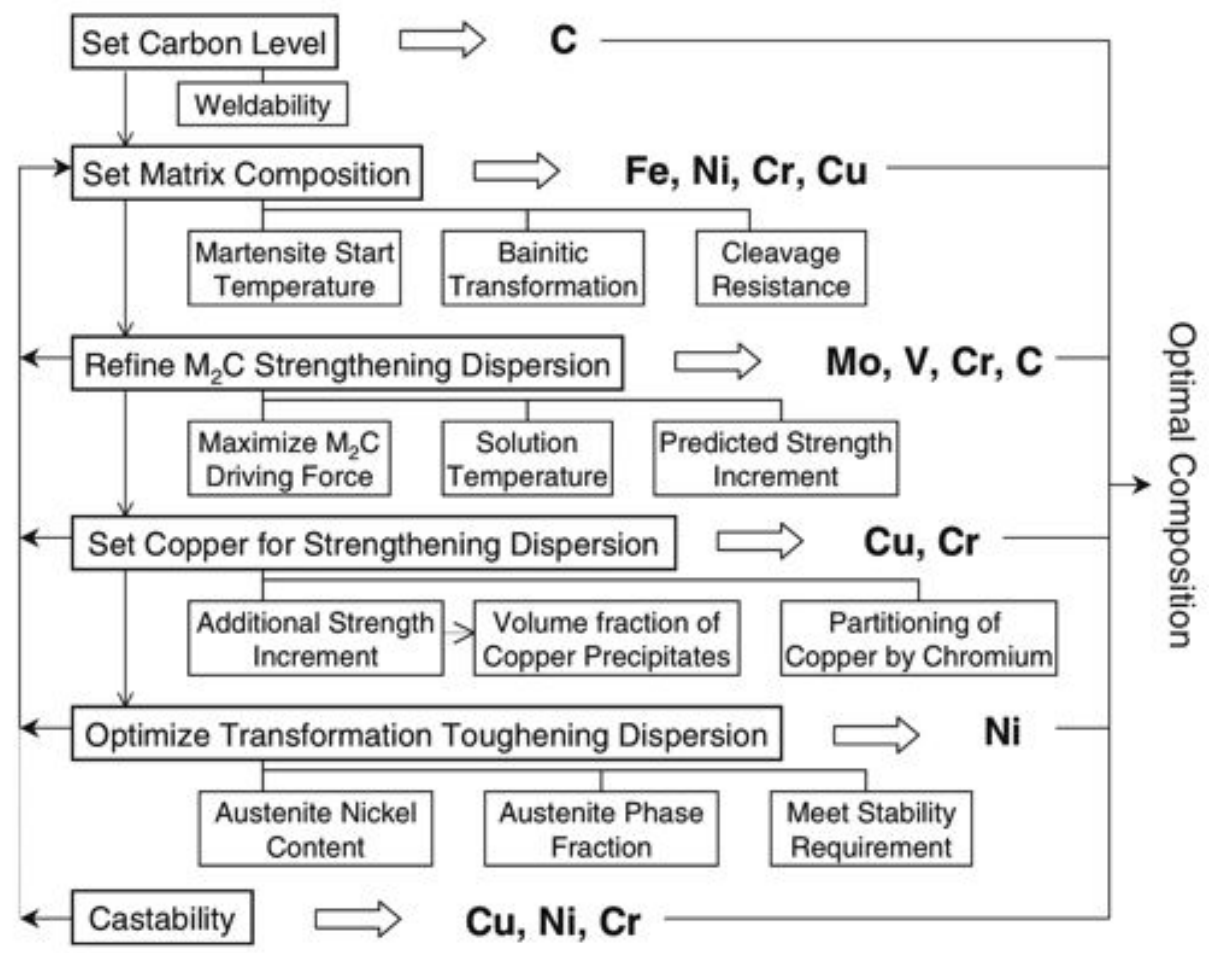

Fig. 1. Design procedure for blast-resistant steel [1], reproduced with permission.

\section{Triumph of Nanotechnology Designs}

There are two aspects of fine structure, the first of which has been known for at least seven decades [4]; small precipitates or clusters of atoms form in a matrix, causing hardening or promoting greater homogeneity during deformation. Following in these footsteps, a major recent development is the commercialisation of strong, formable and weldable steel $[5,7,8]$ that exploits tiny particles of $(\mathrm{Ti}, \mathrm{Mo}) \mathrm{C}$ particles, which lead to an increase in strength from $450 \mathrm{MPa}$ to $\simeq 780 \mathrm{MPa}$ while maintaining an elongation of some $20 \%$. This is a combination of properties that is of importance in the automotive industries. Typical compositions of such steels are in the range [5]:

Fe-0.04C-0.2Si-1.5Mn-(0.02-0.2) Ti-(0-0.4)Mo wt\%. 
The role of molybdenum in the ternary carbide is important - ab initio calculations show that molybdenum should not dissolve in the carbide, but its presence increases the coherency of the precipitate with the matrix, and thereby makes nucleation possible in otherwise difficult circumstances [6]. Indeed, it is observed that molybdenum is rejected from the precipitate as the particle evolves. At the same time, the solubility of titanium in the matrix is smaller in the presence of molybdenum, thereby reducing the coarsening rate of the precipitate during the manufacturing process. The same calculations predict that tungsten should work in the same manner as molybdenum, and work is in progress to see whether there is any advantage in swapping these solutes. The role of molybdenum or tungsten would not have been revealed without first-principles calculations, since thermodynamic data of the type needed for routine phase diagram estimation were not available.

The second aspect of fine structure is related to creating metallic materials which contain a very large density of interfaces per unit volume. The traditional methods, which involve severe deformation in one form or another, for example, equal channel angular processing [9], wire drawing [10], mechanical milling [11], torsion [12] have unpalatable difficulties when it comes to large scale, affordable production $[13,14]$.

This situation has changed with the invention of the world's first bulk nanostructured steel in which the required density of interfaces is introduced purely by solid-state phase transformation, into carbide-free bainite [15]. To understand the nature of this discovery, it is important to appreciate the shape deformation that accompanies the growth of each bainite platelet, an invariantplane strain with a large shear component [16-18]. This constrains the product to be in the form of thin lenticular plates in which the mean free slip-distance is equal to twice the plate thickness. Plastic relaxation of the shape deformation leads to additional refinement by stifling the growth of the platelets [19]. The scale of the structure is known to decrease as the transformation temperature is reduced [20]. The question then arises: what it the lowest temperature at which bainite can be produced, and hence the finest structure attainable by exploiting this transformation?

This is where mathematical models, created on the basis of the atomic mechanisms of transformation and implemented in computer algorithms [21], come into play. Fig. 2 shows that there is in principle no lower temperature limit to bainite formation as long as the martensite-start temperature can also be suppressed, although the kinetics of transformation become slow as room temperature is approached. So an alloy was designed in which bainite could be obtained at $200^{\circ} \mathrm{C}$ in a ten-day heat treatment. The resulting structure is shown in Fig. 3, containing a density of interfaces as large as $10^{8} \mathrm{~m}^{-1}$, a controlling length scale of just $20-40 \mathrm{~nm}$ and credible combinations of strength, ductility, toughness and fatigue resistance. The density of interfaces is as large 
as that obtained in mechanical milling [22] but achieved without deformation or rapid heat treatments. The steel is now commercially available, with many thousands of tonnes already manufactured, for components which are large in all three dimensions.

Details are reviewed elsewhere $[23,13]$ but the discovery has led to promising science which has helped address some long-standing difficulties. The maximum solubility of carbon in ferrite that is in equilibrium with austenite is a little greater than $0.02 \mathrm{wt} \%$ at a temperature of about $600{ }^{\circ} \mathrm{C}$ due to the retrograde shape of the $\alpha / \alpha+\gamma$ phase boundary. It has been known in this context that bainitic ferrite is supersaturated with an excess of carbon [24-27]. This carbon fails to partition into the residual austenite even though the process is not limited by atomic mobility [28]. The accumulated evidence indicates that the excess carbon in the ferrite is reluctant to partition into the residual austenite [24,29-33]. The early interpretations attributed this reluctance to carbon trapping at dislocations. However, recent work has shown conclusively, that excess carbon is present also in defect-free solid solution [34,35].

Computational modelling based on electron theory has explained these anomalies [36]. When transformation occurs by a diffusionless mechanism, the ferrite necessarily inherits carbon atoms in one of the three sub-lattices of octahedral interstices. As a result, it acquires tetragonality. Since the symmetry of the ferrite is changed, so is the solubility of carbon for the tetragonal ferrite which is in contact with austenite. The phase diagrams changes dramatically (Fig. 4) with the solubility of carbon being much larger than that for cubic ferrite which is in equilibrium with austenite. This explains the "excess" carbon that resides in the bainitic ferrite. But more than this, it opens up the possibility of designing tetragonal ferrite, and further calculations are in progress to see how this might be done. Coincidentally, Nematollahi et al. [37] in subsequent work showed that elastically strained ferrite has a greater solubility for carbon when it is in equilibrium with cementite. It seems that computational modelling, in this case inspired by experimental anomalies, is setting the scene for a completely different interpretation of the Fe-C phase diagram.
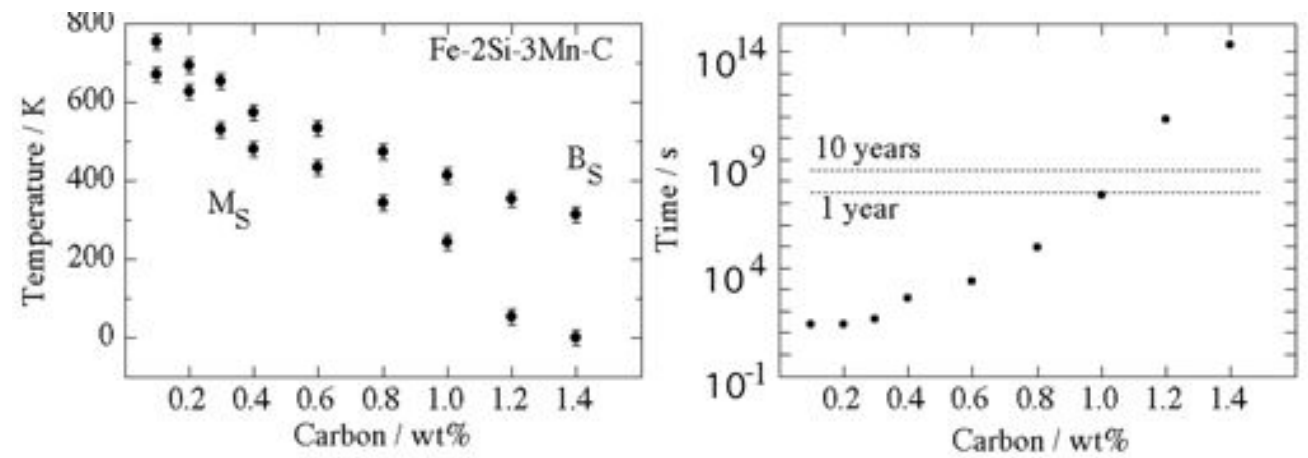

Fig. 2. Calculated transformation start temperatures and time required to initiate bainite. 


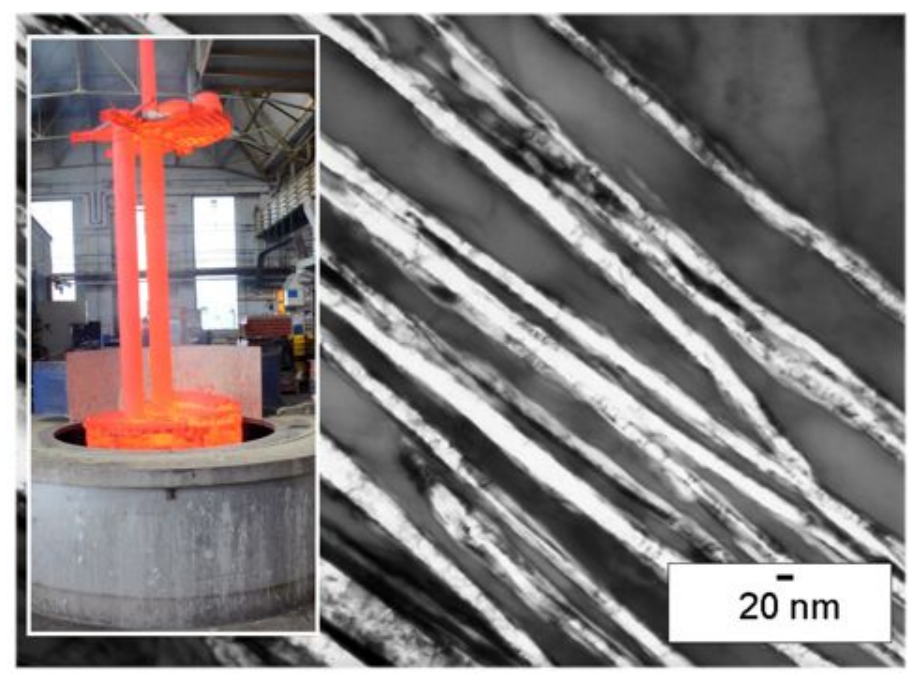

Fig. 3. Extremely thin plates of bainitic ferrite embedded in a matrix of austenite. Inset: large scale processing of new steel.

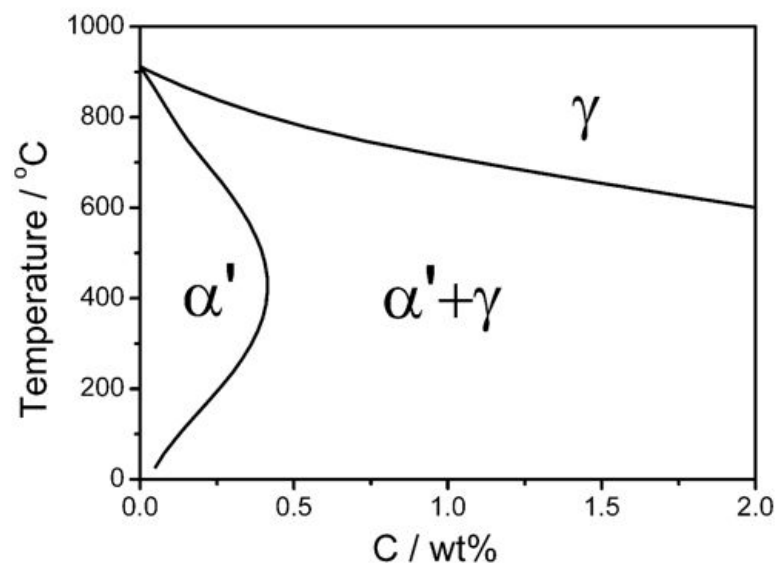

Fig. 4. Binary phase diagrams of the $\mathrm{Fe}-\mathrm{C}$ system for equilibrium between bodycentred tetragonal ferrite and austenite [36]. Note the large increase in the solubility of carbon in the ferrite.

\section{Entire Design: Low-Density Steel}

It does not often happen that computation alone leads to a new concept in steel technology; this is one such example.

Whereas iron has a lower density than nickel and hence is the preferred material for shafts in large aeroengines, a density only $10 \%$ smaller than $7.8 \mathrm{~g} \mathrm{~cm}^{-3}$ would make its specific properties more than competitive against alloys based on aluminium or titanium, while at the same time maintaining an enormous cost advantage. Density can be reduced by alloying with relatively low concentrations of light elements such as silicon, aluminium and magnesium. These solutes work in three ways, by expanding the lattice parameter of iron, via the 
low atomic masses of the solutes, and by changing the equilibrium vacancy concentration. The sort of concentrations required are of the order of 10 at\% or less but apart from density, there are major consequences on the thermodynamic stabilities of the allotropes of iron. An excessive use of aluminium without compensation with carbon would lead to the ferrite being stable at all temperatures where iron is solid, thus eliminating the possibility of controlling structure via phase transformation.

One difficulty is that silicon cannot be used in large concentrations if the quality of the steel surface matters, for example when the aesthetic appearance of the final product is of prime importance. During hot processing, a lowmelting temperature silicon-containing oxide forms and by penetrating the steel provides a mechanical key which makes it difficult to clean the surface. As a consequence, iron oxide patches persist on the surface, later to oxidise into a red coloured form [38-40] which is considered unacceptable. If steels are coated, for example with zinc compounds, then issues arise with the uniformity of the coating.

An attempt was therefore made to achieve the properties and phase fractions typical of TRIP-assisted steels [41], whilst minimising the silicon concentration. Advantage was taken of the vast quantity of published data available to create a neural network model structured on a Bayesian framework [42,43], in combination with genetic algorithms, to computationally discover the optimum composition, processing and property domain consistent with the objective [44]. The Bayesian framework is important because mathematical models of this kind are otherwise unprotected against the dangers of extrapolation into domains where data do not exist. It is of course these domains that are the most interesting for new science; the framework is capable of indicating the extent to which a multitude of models, each capable of reasonably representing known knowledge, behave in extrapolation. This modelling uncertainty can then be interpreted in terms of known physical principles, thereby reducing the possibility of accepting unphysical predictions.

The outcome of the calculations was an entirely unexpected alloy system, surprising in several respects, for example, the predicted chemical composition Fe-0.4C-2Mn-0.5Si-2Al-0.5Cuwt\%. This level of carbon (and carbon equivalent) is unheard of in automotive-body steels. When the material was made, its microstructure was bizarre, identified eventually as consisting of a mixture of $\delta$-ferrite dendrites and interdendritic austenite, Fig. 5a. The properties were remarkable, both in the cast condition [44] and after processing into sheet [45], Fig. 5b. Furthermore, the presence of aluminium reduces the density of the steel; with adaptations in later work, a density reduction of $4 \%$ was achieved, and greater reductions are achievable with a balancing of solutes to ensure that some austenite remains. A further advantage of is that the $\delta$-ferrite persists at all temperatures in the solid-state, so that spot-welding cannot result 
in a fully martensitic structure in any region of the joint. As a consequence, good welding properties are achieved in spite of the large carbon concentration [46]. It is no exaggeration that this new alloy system, designated $\delta$-TRIP steel, emerged from computational modelling alone, which at the outset had the aim of solving a particular surface-engineering issue related to red oxide.
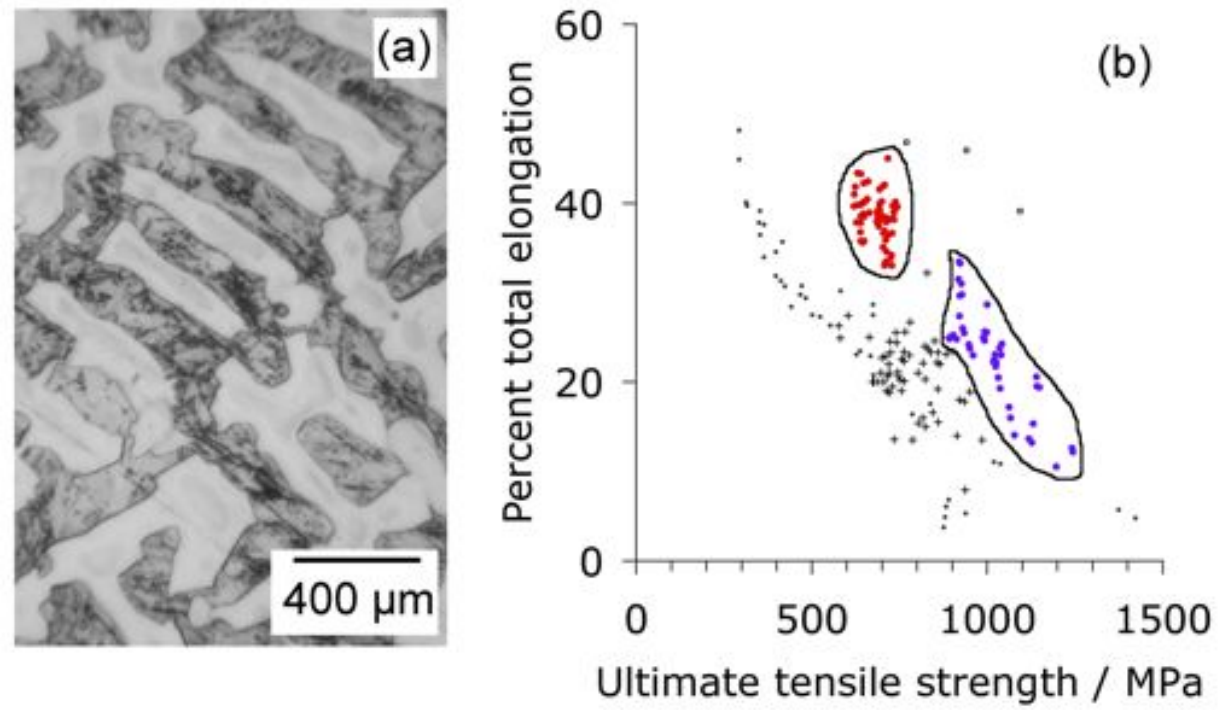

Fig. 5. (a) Dendritic structure of $\delta$-TRIP steel prior to processing. (b) Encircled data show combinations of strength and ductility achieved in comparison with conventional steels.

\section{Predicted Failure}

A handicap of the strong nanostructured bainite is that the steel cannot be welded because untempered, high-carbon martensite is produced in the heataffected zone of any weld. Given that it is the low transformation temperature $\left(200^{\circ} \mathrm{C}\right)$ which results in the fine scale of the structure, an alternative approach would be the suppression of both $B_{S}$ and $M_{S}$ using substitutional solutes rather than a high carbon concentration. Theory based on the nucleation and growth of both bainite and martensite was used to explore this possibility [47]. Computational models based on this theory revealed that it may be impossible to design a low-carbon version because the bainite and martensitestart temperatures merge at large substitutional solute concentrations, Fig. 6 .

The physical reason for this behaviour lies in the fact that the same nucleus can develop into either phase, but the nucleation of bainite requires the partitioning of carbon [48]. It follows that in the absence of carbon, the difference in transformation mechanisms between bainite and martensite diminishes. Experiments validated these results [49]. This represents an example where computational modelling based on phase transformation theory has unfortunately 
predicted correctly that a weldable nanostructured bainite is not a feasible concept.

\section{Summary}

A generic conclusion based on the wider literature is that computational modelling forms an excellent tool to supplement the creation of new alloys and processes, but it is rare indeed that such methods on their own are sufficient to address the complexity of sophisticated materials. More rapid progress is made by moderating claims about the prowess of the methods, and using a combination of data, experience, insight, analytical theory, and computational models to design new materials which at the same time lead to new science. The adjective 'new' is difficult to define, but one interpretation might be that the work stimulates activity.

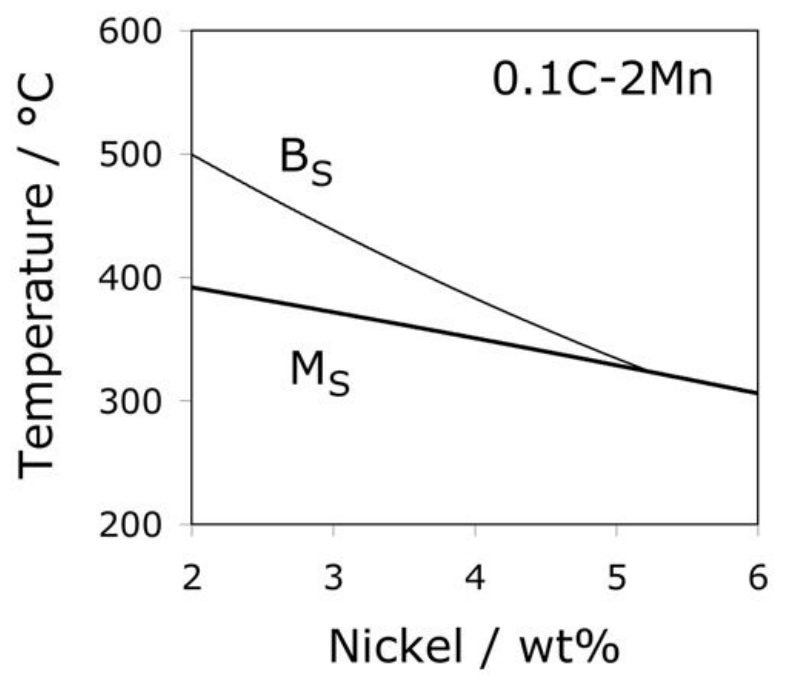

Fig. 6. Calculated transformation temperatures as a function of the nickel concentration [47]. 


\section{References}

[1] A. Saha, G. B. Olson: J. Computer-Aided Mat. Design 14 (2007) 177.

[2] A. Saha, J. Jung, G. B. Olson: J. Computer-Aided Mat. Design 14 (2007) 201.

[3] G. J. McShane, D. D. Radford, V. S. Deshpande, N. A. Fleck: Europ. J.f Mechanics A 25 (2006) 215.

[4] O. B. M. Hardouin Duparc: Metall. \& Mat. Trans. A 41 (2010) 1873.

[5] Y. Funakawa, T. Shiozaki, K. Tomita, Y. Yamamoto, E. Maeda: ISIJ Int. 44 (2004) 1945.

[6] J. H. Jang, C. H. Lee, Y. U. Heo and D. W. Suh: Acta Mater. 60 (2012) 208.

[7] K. Seto, Y. Funakawa, S. Kaneko: JFE GIHO (16) (2007) 28.

[8] C. Chen, H. Yen, F. Kao, W. Li, C. Huang, J. Yang, S. Wang: Mat. Sci. Engng. A 499 (2009) 162.

[9] Z. Horita, M. Furukawa, M. Nemoto, T. G. Langdon: Mat. Sci. Techn. 16 (2000) $1239-1245$.

[10] H. K. D. H. Bhadeshia, H. Harada: App. Surf. Sci. 67 (1993) 328.

[11] S. Takaki: Mat. Sci. Forum 426-432 (2003) 215.

[12] Y. Ivanisenko, I. MacLaren, R. Z. Valiev, H. J. Fecht: Adv. Engng. Mat. 7 (2005) 1011.

[13] H. K. D. H. Bhadeshia: Proc. Roy. Soc. A 466 (2010) 3-18.

[14] H. K. D. H. Bhadeshia: Sci. and Techn. Adv. Mat. (2013) In press.

[15] F. G. Caballero, H. K. D. H. Bhadeshia, K. J. A. Mawella, D. G. Jones, P. Brown: Mat. Sci. Techn. 18 (2002) 279.

[16] T. Ko, S. A. Cottrell: Journal of the Iron and Steel Institute 172 (1952) 307.

[17] E. Swallow, H. K. D. H. Bhadeshia: Mat. Sci. Techn. 12 (1996) 121.

[18] M. Peet, H. K. D. H. Bhadeshia: Metall. Mater. Trans. A 42 (2011) 3344.

[19] S. Chatterjee, H. S. Wang, J. R. Yang, H. K. D. H. Bhadeshia: Mat. Sci. Techn. 22 (2006) 641.

[20] H. K. D. H. Bhadeshia: Bainite in Steels, 2nd edition: Institute of Materials, London, 2001.

[21] U. of Cambridge, NPL: Materials Algorithms Project, URL www.msm.cam.ac.uk/map/mapmain.html

[22] Y. Kimura, H. Hidaka, S. Takaki: Mat. Trans., JIM 40 (1999) 1149. 
[23] F. G. Caballero, H. K. D. H. Bhadeshia: Curr. Opin. Sol. St. Mat. Sci. 8 (2004) 251.

[24] H. K. D. H. Bhadeshia, A. R. Waugh: Acta Metall. 30 (1982) 775.

[25] H. K. D. H. Bhadeshia, A. R. Waugh: in: H. I. Aaronson, D. E. Laughlin, R. F. Sekerka, C. M. Wayman (Eds.), Solid-Solid Phase Trans.: TMS-AIME, Pennsylvania, USA, 1982: 993.

[26] I. Stark, G. D. W. Smith, H. K. D. H. Bhadeshia, Phase Trans. '87: Inst. of Metals, London, U.K., 1988: pp. 211.

[27] I. Stark, G. D. W. Smith, H. K. D. H. Bhadeshia: Metall. Trans. A 21 (1990) 837.

[28] H. K. D. H. Bhadeshia: Bainite in steels: Phase Trans. '87: Inst. of Metals, London, U.K., 1988: 309.

[29] M. Peet, S. S. Babu, M. K. Miller, H. K. D. H. Bhadeshia: Scr. Mater. 50 (2004) 1277.

[30] F. G. Caballero, M. K. Miller, S. S. Babu, C. Garcia-Mateo: Acta Mater. 55 (2007) 381.

[31] C. Garcia-Mateo, M. Peet, F. G. Caballero, H. K. D. H. Bhadeshia: Mat. Sci. Techn. 20 (2004) 814.

[32] F. G. Caballero, M. K. Miller, A. J. Clarke, C. Garcia-Mateo: Scr. Mat. 63 (2010) 442 .

[33] I. B. Timokhina, X. Y. Xiong, H. Beladi, S. Mukherjee, P. D. Hodgson: Mat. Sci. Techn. 27 (2011) 739-741.

[34] F. G. Caballero, M. K. Miller, C. Garcia-Mateo, J. Cornide: J. Alloys Comp. (2012) doi:10.1016/j.jallcom.2012.02.130.

[35] F. G. Caballero, M. K. Miller, C. Garcia-Mateo, J. Cornide, M. J. Santofimia: Scr. Mater. 67 (2012) 846.

[36] J. H. Jang, H. K. D. H. Bhadeshia, D. W. Suh: Scr. Mater. 68 (2012) 195.

[37] G. A. Nematollahi, J. von Pezold, J. Neugebauer, D. Raabe: Acta Mater. . (2013) http://dx.doi.org/10.1016/j.actamat.2012.12.001.

[38] T. Fukagawa, H. Okada, Y. Maehara: ISIJ Int. 34 (1994) 906.

[39] H. Okada, T. Dukagawa, A. Okamoto, M. Azuma, Y. Matsuda: ISIJ Int. 35 (1995) 886-891.

[40] S. Taniguchi, K. Yamamoto, D. Megumi, T. Shibata: Mat. Sci. Engng. A 308 (2001) 250.

[41] P. J. Jacques: Curr. Opin. Sol. St. Mat. Sci. 8 (2004) 259.

[42] D. J. C. MacKay: Neural Comp. 4 (1992) 448. 
[43] H. K. D. H. Bhadeshia: ISIJ Int. 39 (1999) 966.

[44] S. Chatterjee, M. Murugananth, H. K. D. H. Bhadeshia: Mat. Sci. Techn. 23 (2007) 819.

[45] H. L. Yi, K. Y. Lee, H. K. D. H. Bhadeshia: Proc. Roy. Soc. A 467 (2011) 234.

[46] G. S. Jung, K. Y. Lee, J. B. Lee, H. K. D. H. Bhadeshia, D.-W. Suh: Sci. Techn. Weld. Join. 17 (2012) 92.

[47] H. K. D. H. Bhadeshia: Hard bainite: in: J. M. Howe, D. E. Laughlin, J. K. Lee, U. Dahmen, W. A. Soffa (Eds.), Solid-Solid Phase Transformations, TMSAIME, Warrendale, USA: Vol. 1: Pennsylvania, USA, 2005: 469.

[48] H. K. D. H. Bhadeshia: Acta Metall. 29 (1981) 1117.

[49] H.-S. Yang, H. K. D. H. Bhadeshia: Mat. Sci. Techn. 24 (2008) 335. 